\title{
Powder Reuse Cycles in Electron Beam Powder Bed Fusion-Variation of Powder Characteristics
}

\author{
Gitanjali Shanbhag (D) and Mihaela Vlasea *
}

check for updates

Citation: Shanbhag, G.; Vlasea, M. Powder Reuse Cycles in Electron Beam Powder Bed Fusion-Variation of Powder Characteristics. Materials 2021, 14, 4602. https://doi.org/ $10.3390 /$ ma14164602

Academic Editor: Shaun McFadden

Received: 18 July 2021

Accepted: 10 August 2021

Published: 16 August 2021

Publisher's Note: MDPI stays neutral with regard to jurisdictional claims in published maps and institutional affiliations.

Copyright: (c) 2021 by the authors. Licensee MDPI, Basel, Switzerland. This article is an open access article distributed under the terms and conditions of the Creative Commons Attribution (CC BY) license (https:/ / creativecommons.org/licenses/by/ $4.0 /)$.
Department of Mechanical \& Mechatronics Engineering, University of Waterloo, Waterloo, ON N2L 3G1, Canada; gshanbhag@uwaterloo.ca

* Correspondence: mihaela.vlasea@uwaterloo.ca
Abstract: A path to lowering the economic barrier associated with the high cost of metal additively manufactured components is to reduce the waste via powder reuse (powder cycled back into the process) and recycling (powder chemically, physically, or thermally processed to recover the original properties) strategies. In electron beam powder bed fusion, there is a possibility of reusing $95-98 \%$ of the powder that is not melted. However, there is a lack of systematic studies focusing on quantifying the variation of powder properties induced by number of reuse cycles. This work compares the influence of multiple reuse cycles, as well as powder blends created from reused powder, on various powder characteristics such as the morphology, size distribution, flow properties, packing properties, and chemical composition (oxygen and nitrogen content). It was found that there is an increase in measured response in powder size distribution, tapped density, Hausner ratio, Carr index, basic flow energy, specific energy, dynamic angle of repose, oxygen, and nitrogen content, while the bulk density remained largely unchanged.

Keywords: electron beam powder bed fusion; powder reuse; Ti-6Al-4V; powder properties; density; flowability

\section{Introduction}

The performance of a powder-based additively manufactured part highly relies on the quality of the powder feedstock properties. Vock et al. [1] stated that the correlation between bulk powder behavior, powder layer organization, and final part quality is still not well understood. To improve the understanding of the powder-process-part relationship, there is a need to delve into quantifying the variability in powder properties, either as a function of print cycles, handling, or batch-to-batch variability, and investigate their effects on the resulting part properties.

\subsection{Powder Parameters of Interest for Electron Beam Powder Bed Fusion (EB-PBF) Processes}

When looking at powder feedstock for powder bed fusion (PBF) processes, Popov et al. [2] identified that some of the fundamental powder characteristics that need to be assessed include shape, particle size, composition, gas infusions, flowability, tendency to oxidize, and sintering/melting conditions.

Particle morphology has a considerable influence on the powder bed packing density, and consequently on the final component density, where the more irregular the particles, the lower the final density [3]. Higher apparent densities are preferred, as they provide better heat conduction, reducing the risk of sample swelling and overheating [4] in the EB-PBF process. In terms of powder morphology, spherical or regular equiaxed particles, are less cohesive and tend to flow freely, arrange and pack more efficiently than irregular or angular particles [5]. As shape deviates from spherical, the interparticle friction increases and furthermore detrimentally affects the powder flowability and packing efficiency. Powder morphology can also affect the mechanical properties, microstructure, and surface finish of the final component. Consequently, Medina [6] emphasizes that powder morphology 
examination should be performed to identify particle shape, the presence of satellites, foreign particles, or contamination. Most powders for PBF processes are manufactured via atomization. Powders used in the EB-PBF process are typically manufactured via plasma atomization (PA). PA is the process of melting a wire spool feedstock of metal with a plasma torch and cooling it in an inert tower [7]. Powder particles manufactured by PA are usually spherical with minimal satellites and pores.

Particle size distribution (PSD) is a significant parameter in determining the minimum layer thickness, the minimum achievable feature size in final parts, and affects the powderenergy source interaction. The EB-PBF process uses a nominal PSD between $45 \mu \mathrm{m}$ and $105 \mu \mathrm{m}$. Simchi [8] explained that a deviation in the PSD can lead to in-situ powder segregation and layer streaking due to coarser particles being pushed away from the powder bed. This could lead to variations in build quality.

The flowability of the powder is also highly important, to ensure uniform layers when dispensed, distributed, and/or spread onto the build area. It is generally understood that in order to obtain powder layers with homogeneous density, it is important to ensure that the powders are free-flowing and exhibit good flow properties. Powder flowability behavior can be correlated to the size, shape, moisture content, and packing efficiency of the powder particles [9]. For example, larger and spherical particles tend to flow better than smaller and irregular particles. The angle of repose (AOR) can be used to characterize the flowability of powders [1]. The AOR is affected by various cohesive forces: Van der Waals, electrostatic, and capillary, as well as the contact forces between powder particles. Teferra [10] states that powders that show a low AOR are categorized as non-cohesive, highly flowable powders and can be transported using gravitational force or extremely little energy. Powders with high AOR values are characteristic of cohesive powders and may lead to sporadic or intermittent flow. Powder rheometry characterization provides a suite of in-depth powder performance metrics such as tap density, apparent density, dynamic flow testing, dynamic angle of repose, shear index, and cohesiveness.

Inert gas fusion analysis (i.e., LECO) provides quantitative data on the absolute oxygen and nitrogen content in the powders. This analysis is essential to understand whether the evolution of the oxygen and nitrogen content in the reused Ti- $6 \mathrm{Al}-4 \mathrm{~V}$ powder is within the allowable concentration limits defined by ASTM 2924-14 [11] (i.e., $<0.20 \mathrm{wt} . \%$ for oxygen and $<0.05 \mathrm{wt} . \%$ for nitrogen).

It is of interest to quantify the effect of powder morphology, PSD, powder flowability, oxygen, and nitrogen content on the EB-PBF processes as a function of powder reuse.

\subsection{Powder Parameter Studies in EB-PBF of Ti-6Al-4V}

There has been an increasing interest in fabricating parts using EB-PBF. To continually improve the process, it is important to identify, address, and overcome some of the process limitations. Debroy et al. [12] have identified that the cost of a manufactured part in PBF processes is essentially contributed to by the additive manufacturing equipment, feedstock material, manufacturing, and indirect costs [13]. Specifically, when looking at the cost of one build via EB-PBF, Baumers et al. [14] have identified that the feedstock powder makes up to $\sim 28 \%$ of the total cost of the build. Therefore, we can conclude that the cost of the EB-PBF process heavily relies on the reusability of powders and may not be cost-affordable for complex applications if the unmelted powder in the build bed is not reused. Thus, the evaluation of the maximum number of allowable powder reuse cycles is an essential factor to assess process affordability for a specific part or application. Reusing Ti-6Al-4V powder in EB-PBF can result in changes in the chemical composition, powder morphology, powder size distribution, and flowability, resulting in changes in the properties of the solidified material [15-17].

Powder morphology has been observed to be modified after reusing Ti-6Al-4V powders in EB-PBF. Tang et al. [18] observed that the particles became less spherical, had fractures, protrusions, and concave sites after reusing. They also observed an increase in surface roughness and distortions in the final part. Strondl et al. [5] observed irregularities, 
impact marks, satellites, and stacked particles in the recycled powder. Similar findings were reported by Mohammadhosseini et al. [19], where satellites and aggregation of particles in the reused powder were observed.

Some studies also reported flowability results for virgin and reused powders. Tang et al. [18] observed that the reused powder showed lower flowability when measured by Hall flowmeter and attributed this to the blasting process, which led to irregular particle morphology and impact marks on the particle surface. Contradictory to this, Mohammadhosseini et al. [19] observed no change in the flowability, when measured by Hall flowmeter and Carney funnel, after reuse.

Studies on the effect of reusing powder on chemical composition showed that reusing Ti-6Al-4V can lead to an increase in oxygen content. Sun et al. [20] observed that after 30 reuses, there was a $35 \%$ increase in oxygen content in the reused powder, from $0.15 \mathrm{wt} . \%$ in virgin powder to $0.20 \mathrm{wt} . \%$. Petrovic and Niñerola [21] observed that the oxygen content exceeded the $0.20 \mathrm{wt} . \%$ limit after 12 reuse cycles, where the initial oxygen content in the virgin powder was $0.14 \mathrm{wt} . \%$. They attributed this increase to the humidity pickup from the inner walls of the machine. Similarly, Tang et al. [18] observed that the oxygen content increased from $0.08 \mathrm{wt} . \%$ to $0.19 \mathrm{wt} . \%$ after 21 reuse cycles. They attributed this oxygen increase to exposure of powder to the air, including processing in the powder recovery system and sieving. An increase in oxygen content typically results in an increase in the strength but lowers the toughness and ductility of the final part [15]. Furthermore, Leung et al. [22] observed that the oxides in an oxidized powder may enable pore formation (and subsequently stabilize the pores) during the manufacturing process. Therefore, the mechanical properties of the parts will be varying with the number of reuse cycles.

Based on these studies, a powder suitability criterion can be created for reused powders (see Table 1), for use in the EB-PBF process, to understand what type of powder performance metric behavior is suitable with respect to the morphology, size distribution, sphericity, basic flow energy, specific energy, density, Hausner ratio, Carr index, cohesive index, angle of repose, oxygen content, and nitrogen content.

EB-PBF machines store about $100-180 \mathrm{~kg}$ of powder (depending on the machine model) in the hoppers and it is often impossible to refill these hoppers with powder from the same reuse cycle. Hence blends of powders, either a mixture of virgin and reused or a mixture of different reuse cycles, are frequently used for manufacturing parts and such blend performances also need to be evaluated. These practices often pose challenges in isolating the effects of powder reuse in the above-mentioned studies. In addition, most published studies focus on assessing the effect of powder reuse on only a few specific powder performance metrics. Therefore, there is a need to assess the different powder characterization techniques and obtain the various powder performance metrics associated with these techniques. This needs to be done by precisely isolating the powder blends used in the build, as well as performing a comprehensive study on the effects of powder reuse on powder properties. Thus, the current comprehensive manuscript aims at advancing the authors' preliminary study [23], by assessing different powder characterization techniques and obtaining the various powder performance metrics associated with these techniques to identify the key performance features of reused powder and powder blends. 
Table 1. Powder suitability criteria for use in the EB-PBF process.

\begin{tabular}{|c|c|c|c|c|}
\hline $\begin{array}{c}\text { Powder } \\
\text { Characteristic }\end{array}$ & Requirements & $\begin{array}{l}\text { What Other } \\
\text { Characteristics does This } \\
\text { Property Have an } \\
\text { Influence on }\end{array}$ & $\begin{array}{l}\text { Performance Metrics } \\
\text { That can Help Assess } \\
\text { The Powder Property }\end{array}$ & $\begin{array}{l}\text { Should This } \\
\text { Performance Metric } \\
\text { be Maximized }(\uparrow) \text {, } \\
\text { Minimized }(\downarrow) \text { or } \\
\text { Kept Constant }(\leftrightarrow)\end{array}$ \\
\hline Morphology & $\begin{array}{c}\text { Spherical and equiaxed to increase } \\
\text { flowability and avoid interparticle friction } \\
\text { and mechanical interlocking }\end{array}$ & $\begin{array}{l}\text { Powder bed packing } \\
\text { density and the final } \\
\text { component density, } \\
\text { surface finish }\end{array}$ & Sphericity & $\uparrow$ \\
\hline $\begin{array}{l}\text { Apparent } \\
\text { density }\end{array}$ & $\begin{array}{c}\text { Should be high for improved heat conduction } \\
\text { in the EB-PBF process }\end{array}$ & $\begin{array}{l}\text { Heat conduction, sample } \\
\text { swelling and overheating }\end{array}$ & $\rho_{0}$ & $\uparrow$ \\
\hline Compressibility & $\begin{array}{c}\text { High compressibility is desirable to be able to } \\
\text { achieve higher packing density in the } \\
\text { powder bed }\end{array}$ & $\begin{array}{l}\text { Powder bed packing } \\
\text { density, layer thickness, } \\
\text { heat conduction }\end{array}$ & Carr index $(C)$ & $\downarrow$ \\
\hline $\begin{array}{l}\text { Particle Size } \\
\text { distribution } \\
\text { (PSD) }\end{array}$ & $\begin{array}{l}\text { Stay within the manufacturer's size range } \\
\text { and not drastically increase in order to obtain } \\
\text { small feature sizes and thinner powder layers }\end{array}$ & $\begin{array}{l}\text { Minimum layer thickness, } \\
\text { minimum achievable } \\
\text { feature size, build quality, } \\
\text { surface finish }\end{array}$ & $\mathrm{D}_{10}, \mathrm{D}_{50}$ and $\mathrm{D}_{90}$ values & $\leftrightarrow$ \\
\hline $\begin{array}{l}\text { Chemical } \\
\text { composition }\end{array}$ & $\begin{array}{c}\text { The oxygen and nitrogen concentration } \\
\text { should stay within allowable } \\
\text { concentration limits }\end{array}$ & $\begin{array}{l}\text { Mechanical properties } \\
\text { such as toughness, } \\
\text { ductility of final parts, } \\
\text { embrittlement }\end{array}$ & $\begin{array}{l}\text { Oxygen (in wt. } \% \text { ) and } \\
\text { nitrogen (in wt. \%) }\end{array}$ & $\downarrow$ \\
\hline Spreadability & $\begin{array}{l}\text { A dynamic cohesive index closer to zero } \\
\text { corresponds to a non-cohesive powder. A } \\
\text { cohesive powder leads to a sporadic or } \\
\text { intermittent flow while a non-cohesive } \\
\text { powder leads to a regular flow }\end{array}$ & \multirow{5}{*}{$\begin{array}{l}\text { Powder bed packing } \\
\text { density, powder layer } \\
\text { uniformity, rake-ability, } \\
\text { easy flow in the hoppers } \\
\text { (i.e., powder storage). } \\
\text { Decreased spreadability } \\
\text { and flowability may } \\
\text { contribute to more defects } \\
\text { in the final part }\end{array}$} & Cohesive index (CI) & $\downarrow$ \\
\hline \multirow{4}{*}{ Flowability } & \multirow{4}{*}{$\begin{array}{l}\text { Highly flowable powder minimizes the risk } \\
\text { of mechanical interlocking and friction } \\
\text { between particles and allows for smooth } \\
\text { operation while raking and for uniform and } \\
\text { homogenous distribution over the build plate }\end{array}$} & & Hausner ratio $\left(H_{r}\right)$ & $\downarrow$ \\
\hline & & & Basic flow energy (BFE) & $\downarrow$ \\
\hline & & & Specific energy (SE) & $\downarrow$ \\
\hline & & & & $\downarrow$ \\
\hline
\end{tabular}

\section{Materials and Methods}

The Grade 5 plasma-atomized Ti-6Al-4V powder (Batch number: P1321, Advanced Powders and Coatings, Montreal, Quebec, Canada) was obtained in its pre-alloyed form with a size range of 45-105 $\mu \mathrm{m}$. The chemical composition of the powder conforms to ASTM F2924 for a Grade 5 Ti-6Al-4V powder (according to batch information provided by the powder supplier). A total of seven powder types were assessed for this study. The powder obtained from the supplier is referred to as the virgin powder (henceforth known as Genesis 0 or $G_{0}$ ). It should be noted that the $G_{0}$ powder did not undergo any processing in the EB-PBF machine, blasting in the powder recovery system, or sieving to remove the fine powder particles. Therefore, this powder type may be considered an anomaly for the various powder characterization. Nevertheless, the results for $G_{0}$ are presented in order to compare the results for all other powder types and use $G_{0}$ as the baseline. Powder that was used once (Genesis 1 or $G_{1}$ ), was passed through a vibrating sieve (mesh size $-140+325$, i.e., $44 \mu \mathrm{m}$ to $105 \mu \mathrm{m})$ to recover the powder for reuse. Genesis $2\left(G_{2}\right)$ and Genesis $3\left(G_{3}\right)$ powders were similarly obtained after printing parts with $G_{1}$ and $G_{2}$ powder, respectively. For every powder type, approximately $500 \mathrm{~g}$ of powder was collected in a metal can. These cans were subsequently sealed and rolled/tumbled, on a jar-mill (Labmill 8000, Gardco, Pompano Beach, FL, USA), at 40 revolutions per minute (RPM), for $24 \mathrm{~h}$ in order to homogenize the sample before conducting any characterization. $G_{1}$ and $G_{2}$ powders were blended in equal wt.\% to obtain the $\mathrm{GB}_{12}$ blend and compare its properties with the other powder types. Similarly, $\mathrm{GB}_{13}$ and $\mathrm{GB}_{23}$ blends were obtained based on equal wt.\% of powder constituents. Table 2 summarizes the nomenclature and description of the various powder types investigated for the current study. The individual powder geneses were first collected in metal cans and rolled for $24 \mathrm{~h}$, as mentioned earlier. These were then mixed in equal parts to create the respective blends. This blended powder was also collected in 
metal cans, sealed, and rolled for another $24 \mathrm{~h}$ to ensure homogeneity and proper mixing in the blend. Therefore, the blended powders see a total rolling/tumbling time of $48 \mathrm{~h}$ as compared to $24 \mathrm{~h}$ for the unblended powders. All printing was done on an Arcam A2X machine using the default parameters provided for Ti-6Al-4V (Theme 5.2.52, Arcam A2X, GE Additive, Gothenburg, Sweden). To ensure that a consistent beam scanning strategy was used for all builds, the parts built were constant across the 3 printing cycles.

Table 2. Nomenclature and description of the various powder types investigated for the current study.

\begin{tabular}{cc}
\hline Powder Type & Description \\
\hline $\mathrm{G}_{0}$ & Virgin powder \\
$\mathrm{G}_{1}$ & Powder that was used 1 time \\
$\mathrm{G}_{2}$ & Powder that was used 2 times \\
$\mathrm{G}_{3}$ & Powder that was used 3 times \\
$\mathrm{GB}_{12}$ & $50 \% \mathrm{G}_{1}+50 \% \mathrm{G}_{2}$ \\
$\mathrm{~GB}_{13}$ & $50 \% \mathrm{G}_{1}+50 \% \mathrm{G}_{3}$ \\
$\mathrm{~GB}_{23}$ & $50 \% \mathrm{G}_{2}+50 \% \mathrm{G}_{3}$ \\
\hline
\end{tabular}

In order to assess the powder particle morphology, field emission microscopy (SEM, Zeiss Ultra and Tescan VEGA3, Munich, Germany and Pittsburgh, PA, USA, respectively) observations were performed. A Camsizer X2 (Retsch GmbH, Düsseldorf, Germany) was used to measure the PSD of the various powder types. Two grams of powder was used for each test performed on the Camsizer. The system uses the principle of digital image processing [24], where the dispersed particles pass in front of LED light sources and their shadows are captured with two digital cameras. The Retsch software (Version 6.7, Retsch $\mathrm{GmbH}$, Düsseldorf, Germany) analyzes the size of each particle captured by the camera and calculates the respective distribution curves.

Powder rheology was investigated using a powder rheometer (FT4, Freeman Technology, Gloucestershire, UK), rotating drum (Granudrum; Granutools, Liège, Belgium) and an automated tap density instrument (GranuPack; Granutools, Liège, Belgium). Performance metrics were collected, such as the basic flow energy (BFE), specific energy (SE), bulk density $\left(\rho_{0}\right)$, tap density after 500 taps $\left(\rho_{500}\right)$, Hausner ratio $\left(H_{r}\right)$, and Carr index $(C)$. To characterize the resistance to flow, eleven test cycles were run with a condition cycle run between each test. A total of $25 \mathrm{~g}$ of powder was used for each test performed on the FT4. During the tests, the precision blade was rotated downwards and upwards through the fixed volume of powder to establish a flow pattern, where the resistance of the powder to the blade yielded the bulk flow properties. The BFE is defined as the energy required to displace a powder when the blade is moving downward, and the powder is constrained. As described by Freeman and Fu [25], the SE measures the powder's flowability as the blade rotates upward and the powder is unconfined as there is no enclosure at the top of the vessel. The GranuPack measures the evolution of the powder density as a function of the tap number to obtain a compaction curve (as shown in Figure 1), which is used to calculate the $H_{r}$ and $C$ values. $35 \mathrm{~g}$ of powder was used for each test performed on the GranuPack. $H_{r}$ is a number that is correlated to the flowability of a powder and is calculated using the formula $H_{r}=\rho_{500} / \rho_{0}$, where $\rho_{500}$ is the tapped density of the powder after 500 taps and $\rho_{0}$ is the initial bulk density of the powder. $C$ is related to the compressibility of a powder and is calculated by the formula $100\left(\rho_{500}-\rho_{0}\right) / \rho_{500}$, where $\rho_{0}$ is the initial bulk density of the powder and $\rho_{500}$ is the final tapped density of the powder after 500 taps. 


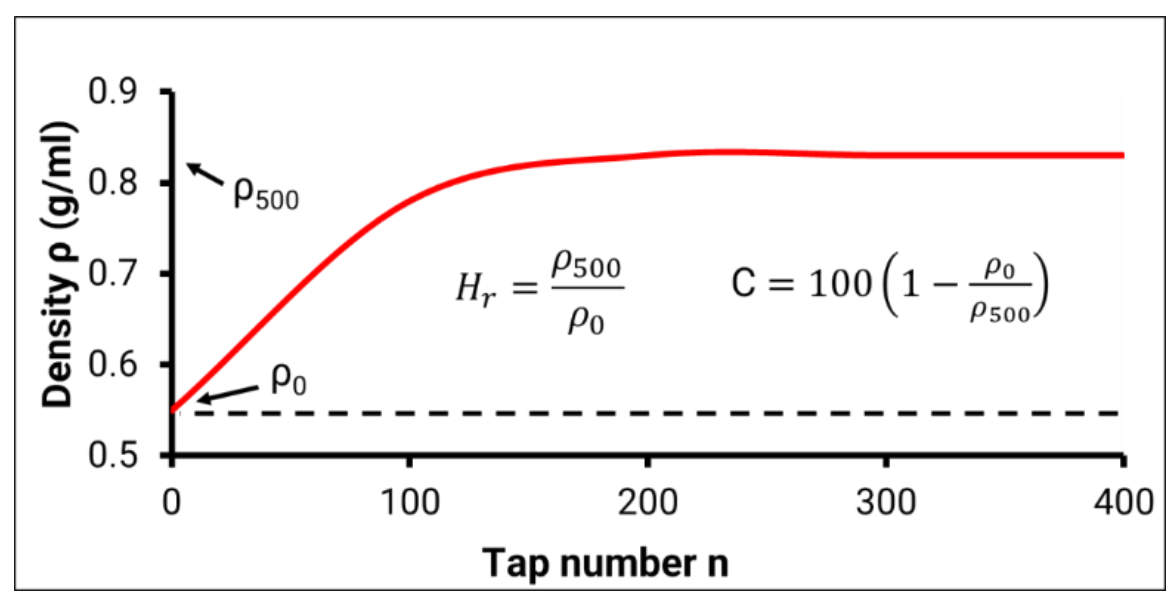

Figure 1. Example of compaction curve obtained by GranuPack—illustrating bulk density $\left(\rho_{0}\right)$, tap density $\left(\rho_{500}\right)$, Hausner ratio $\left(H_{r}\right)$, and Carr index $(C)$.

The GranuDrum instrument (Granutools, Liège, Belgium) is used to determine the dynamic angle of repose and the cohesive index. The GranuDrum is composed of a horizontal drum half-filled with powder that rotates around its axis at an angular velocity ranging from $2 \mathrm{rpm}$ to $60 \mathrm{rpm}$. A total of $50 \mathrm{~g}$ of powder was used for each test performed on the GranuDrum. In total 17 velocities were tested, from $2 \mathrm{rpm}$ to $20 \mathrm{rpm}$ at increments of $2 \mathrm{rpm}$ followed by $25 \mathrm{rpm}$ to $60 \mathrm{rpm}$ at increments of $5 \mathrm{rpm}$. To minimize internal sequence effects, a different velocity sequence was used for each replicate (3 replicates in total) such that the sequences for all replicates are minimally correlated. A camera takes snapshots for each angular velocity and the software calculates the flowing angle of powder (or AOR) and the cohesive index $(\mathrm{CI})$ values.

Chemical analysis for the various powders were performed using inert gas fusion on a LECO TCH 600 (Leco Corporation, St. Joseph, MI, USA) instrument to analyze the oxygen and nitrogen content in the powders. $3 \mathrm{~g}$ of powder was used for each test performed on the LECO TCH 600. All powder characterisation experiments were performed in triplicate and the average values are reported in this manuscript.

\section{Results}

As the number of reuse cycles increases, properties such as chemical composition, surface features (e.g., surface roughness and overall particle roundness), and physical and thermal properties are expected to change. Therefore, understanding the powder behavior with reuse is important for both cost and quality control.

\subsection{Observations of Changes in Powder Properties with Reuse Cycles}

The powder is predominantly spherical in its as-received (or virgin) condition. Figure 2 presents the high magnification SEM micrographs for all different powder types. These micrographs help define and depict defects such as satellites (Figure 2a), elongated particles (Figure 2c), broken particles (Figure 2g,h,i,k), deformed particles (Figure 2b,f), particle with molten specks (Figure 2d), clip-clap (Figure 2e), shattered particles (Figure 21), and agglomerates (Figure 2j). The nomenclature and morphology of $\mathrm{G}_{0}, \mathrm{G}_{1}, \mathrm{G}_{2}$ and $\mathrm{GB}_{12}$ powder types have been previously described in $[23,26]$. Other authors have also reported defects such as non-spherical particles and presence of agglomerates after reusing. Sun et al. [20] observed noticeable deformations and distortions on the surface of reused EB-PBF powder particles. Cordova et al. [27] observed that reused powder, in laser PBF processes, exhibits a deformation towards a teardrop shape and a rougher surface due to remelting. 


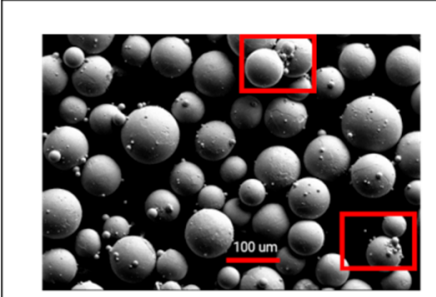

(a) Satellites

$\left(G_{0}\right.$ at $\left.150 X\right)$

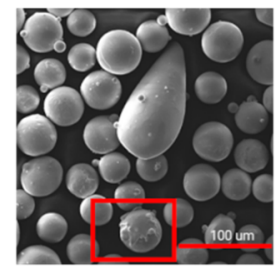

(e) Clip-Clap

( $\mathrm{GB}_{13}$ at $500 \mathrm{X}$ )

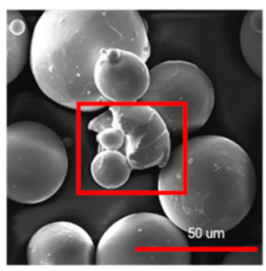

(i) Broken particle $\left(\mathrm{GB}_{23}\right.$ at $\left.1000 \mathrm{X}\right)$

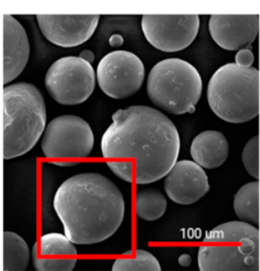

(b) Deformed particle $\left(\mathrm{G}_{1}\right.$ at $\left.750 \mathrm{X}\right)$

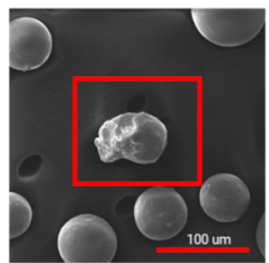

(f) Deformed particle $\left(\mathrm{GB}_{13}\right.$ at $750 X)$

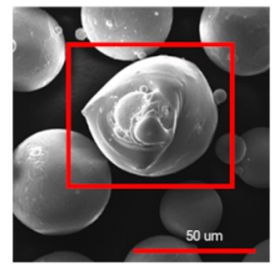

(j) Agglomerate $\left(\mathrm{GB}_{23}\right.$ at $\left.1000 \mathrm{X}\right)$

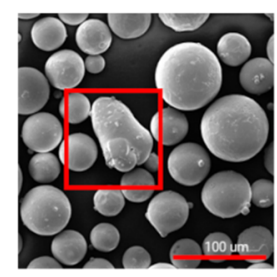

(c) Elongated particle (d) $\left(\mathrm{GB}_{12}\right.$ at $\left.500 \mathrm{X}\right)$

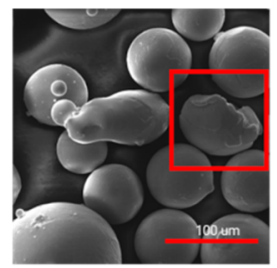

(g) Broken particle $\left(\mathrm{GB}_{13}\right.$ at $\left.1000 \mathrm{X}\right)$

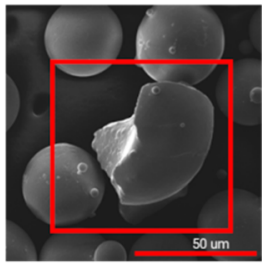

(k) Broken particle $\left(\mathrm{G}_{3}\right.$ at $\left.1000 \mathrm{X}\right)$

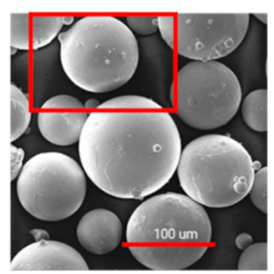

(d) Particle with molten specks $\left(G_{2}\right.$ at $\left.750 X\right)$

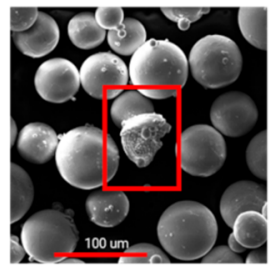

(h) Broken particle $\left(\mathrm{GB}_{23}\right.$ at $\left.500 \mathrm{X}\right)$

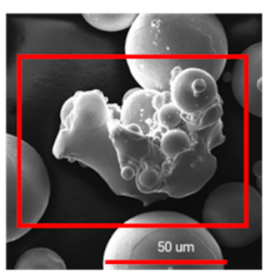

(I) Shattered particle $\left(G_{3}\right.$ at $\left.1000 \mathrm{X}\right)$

Figure 2. SEM micrographs for all powder types depict (a) satellites in $G_{0}$ powder; (b,f) deformed particle in $G_{1}$ and $G_{13}$ powders, respectively; (c) elongated particle in $\mathrm{GB}_{12}$ powder; (d) particle with molten specks in $\mathrm{G}_{2}$; (e) clip-clap in $\mathrm{GB}_{13}$ powder; $(\mathbf{g}, \mathbf{h}, \mathbf{i}, \mathbf{k})$ broken particles in $\mathrm{GB}_{13}, \mathrm{~GB}_{23}$ and $\mathrm{G}_{3}$ powders; $(\mathbf{j})$ agglomerate in $\mathrm{GB}_{23}$ powder and (l) shattered particle in $\mathrm{G}_{3}$ powder. Nomenclature used to describe these micrographs was first defined by Popov et al. [26]. A Zeiss Ultra SEM instrument was used to capture the image shown in (a); all other images were captured using the Tescan VEGA3 instrument.

The deformed, broken, clip-clap, and shattered particle defects are attributed to the recovery via the blasting procedure. The homogenization of powder via tumbling on a jar-mill may result in numberless collisions between particles, and in friction and wear in the presence of air, and therefore the tumbling procedure may be another reason for these defects. The particles with molten specks and elongated particles are attributed to the temperature conditions that lead to overheating and smelting of the particles and satellites [26]. The agglomeration of powders is attributed to the high temperature of the process. Agglomerated particles result from the diffusion bonding obtained during preheating (to allow charge dissipation through the powder bed and reduce particle ejections resulting from the interaction of the electron beam during melting). The SEM micrographs (Figure 2) make it qualitatively evident that recovering and reusing the powder from the powder cake has changed the powder morphology significantly.

Figure 3 shows the $D_{10}, D_{50}$, and $D_{90}$ values of the different powders investigated. The $\mathrm{D}_{50}$ (median value), is described as the diameter where half of the population lies below this value. Similarly, $90 \%$ and $10 \%$ of the distribution lie below $\mathrm{D}_{90}$ and $\mathrm{D}_{10}$, respectively. It is worth noting that the $\mathrm{G}_{0}$ powder has not undergone any processing in the EB-PBF machine, nor blasting or recovery through the sieve. This contributes to the discrepancies below $44 \mu \mathrm{m}$ in the PSD of $\mathrm{G}_{0}$ when compared to the other powder types. As expected, the $\mathrm{D}_{10}, \mathrm{D}_{50}$, and $\mathrm{D}_{90}$ values for $\mathrm{GB}_{12}, \mathrm{~GB}_{13}$, and $\mathrm{GB}_{23}$ lie between their respective genesis powders. This is because the authors ensured that the powder blends were made from 
equal wt.\% of powder constituents and mixed thoroughly before characterization. The $\mathrm{D}_{10}$, $D_{50}$, and $D_{90}$ values for the individual genesis powders (i.e., $G_{1}, G_{2}, G_{3}$ ) show an increasing trend (Figure 3). In other words, one can say that the $D_{10}, D_{50}$, and $D_{90}$ values increase with an increase in number of reuse cycles. Specifically, a $7 \%, 10 \%$, and $7 \%$ increase was observed in the $D_{10}, D_{50}$, and $D_{90}$ values, respectively, for $G_{3}$ powder when compared to the $\mathrm{G}_{0}$ powder.

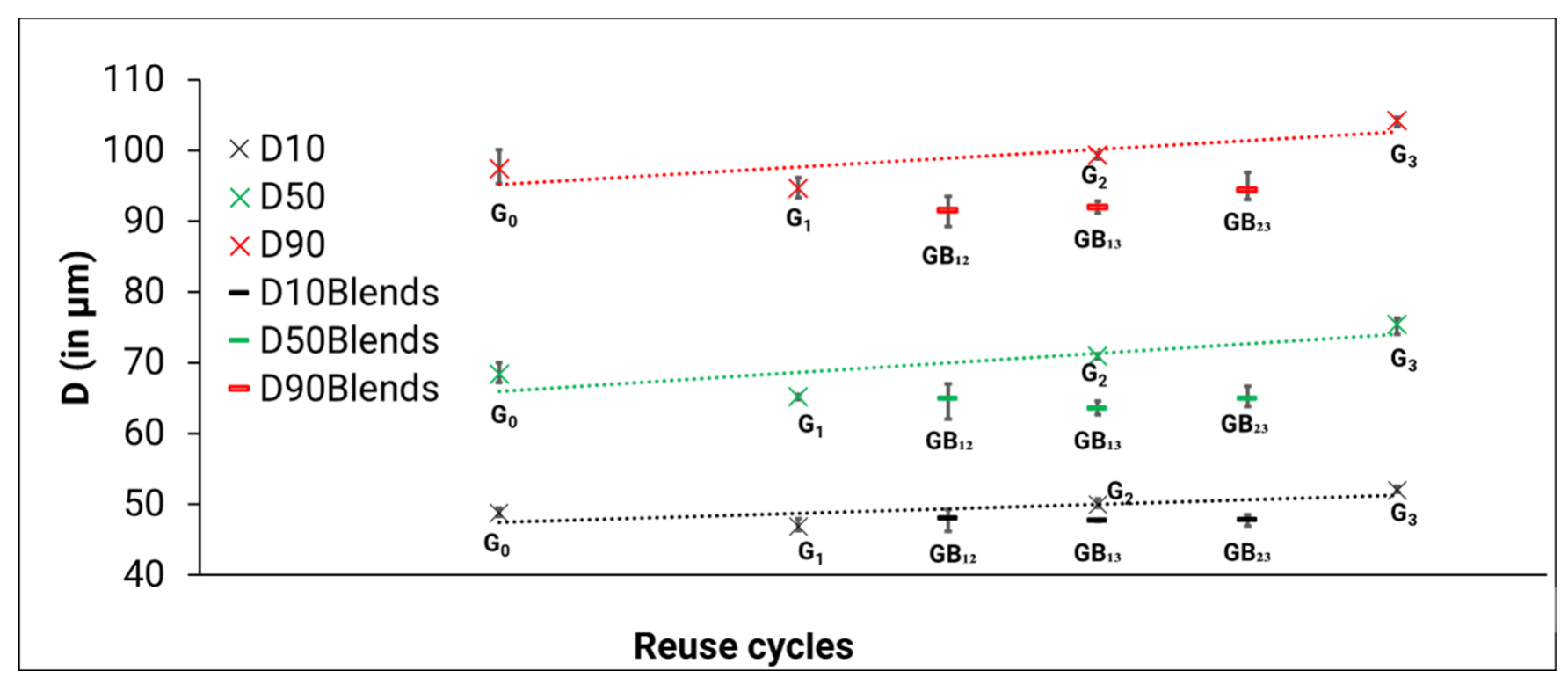

Figure 3. $D_{10}, D_{50}$ and $D_{90}$ values; for all powder types. Error bars represent the min-max range.

Slotwinski et al. [28] also reported an increase in particle size with increasing number of reuse cycles in laser powder bed fusion (LPBF). They associated this observation to the consolidation and loss of the small particles. Grainger [29] also noticed a disappearance of smaller particles with an increase in the number of powder reuse cycles in LPBF. Although the LPBF process does not use the same energy source, nor result in a powder cake after sintering, the powders are exposed to sputter and undergo a sieving process to recover the powders for reuse; similarities in trends with EB-PBF are observed in the present work.

The bulk density $\left(\rho_{0}\right)$ measured with the GranuPack instrument indicates that the values for the individual genesis powders and the powder blends do not significantly change with reuse (as seen in Figure 4a). Similar results were observed by Tang et al. [18], where the $\rho_{0}$ remained unchanged after 21 reuse cycles. A powder with good flowability is usually characterized by a high $\rho_{0}$ value. This is because free-flowing particles (with minimum interparticle adhesion) would be able to find an optimum arrangement and pack densely, therefore corresponding to a higher $\rho_{0}$ value. For such a powder, the possibility of a density increase during tapping is limited, and therefore the ratio of tap density $\left(\rho_{500}\right)$ to $\rho_{0}$ (also known as the Hausner ratio) would be close to unity. 


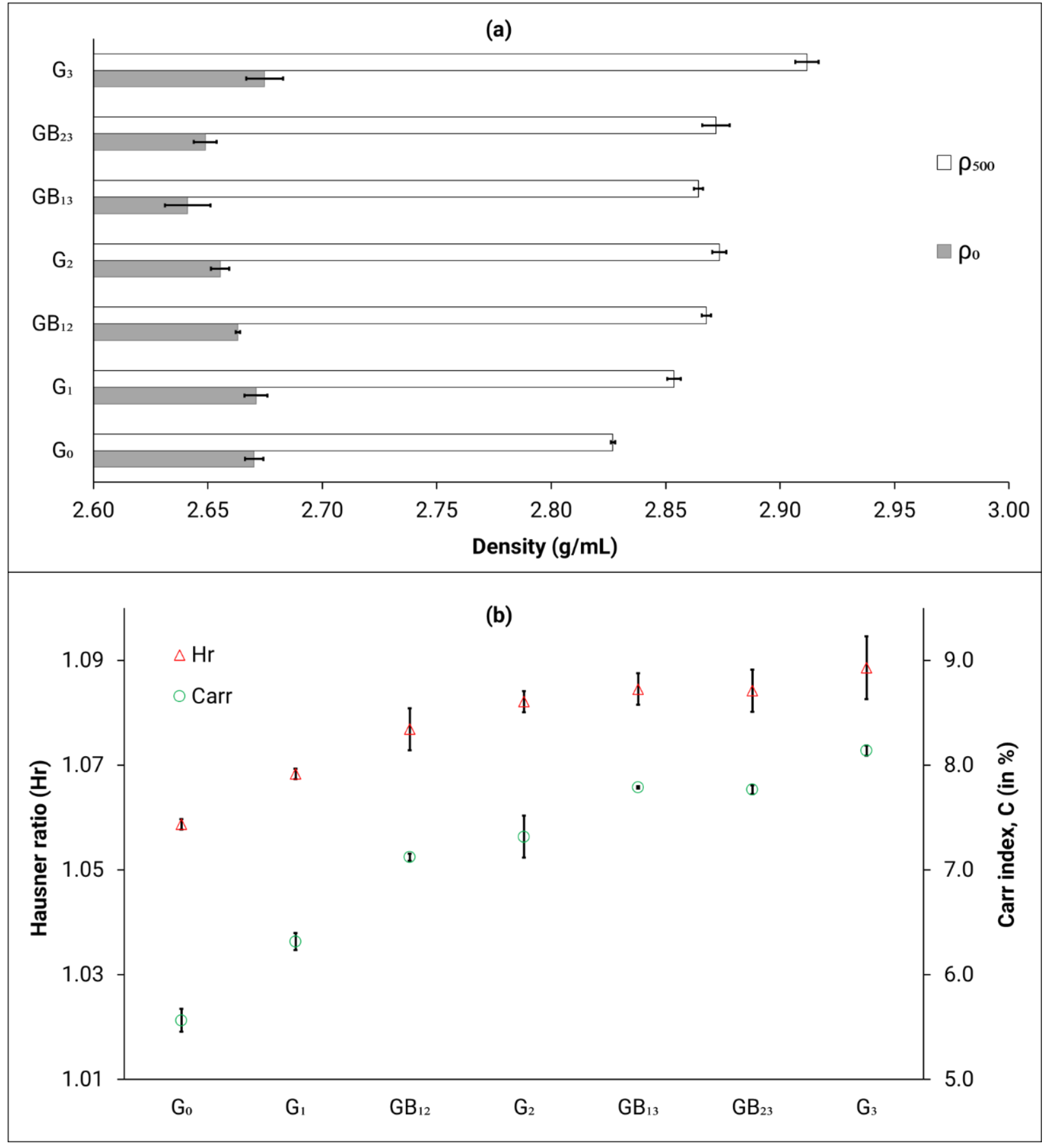

Figure 4. (a) $\rho_{0}$ and $\rho_{500}$ values (b) $H r$ and $C$ values; for all powder types. Error bars represent the standard deviation.

The $\rho_{500}$ values are presented in Figure $4 \mathrm{a}$. It is observed that the tap density increases with the number of reuse cycles. Specifically, a $3 \%$ increase was observed in the $\rho_{500}$ value for $\mathrm{G}_{3}$ powder when compared to the $\mathrm{G}_{0}$ powder. For the most part, the tap density values for the powder blends lie between their respective genesis powders. The difference between the bulk and tapped densities is significant and increases with an increase in number of reuse cycles. Interparticulate interactions are usually larger for poorly flowing powders and therefore a greater difference between the bulk and tapped densities is observed [27]. This suggests that the powder flowability is reduced when the number of reuse cycles increases.

The Carr index $(C)$ is the measure of the extent to which a powder can be compressed (without deforming the particles). The compressibility of the powder is expected to affect the continuity and uniformity of the powder layer, with lower $C$ values in favor of the 
formation of denser layers. As mentioned earlier, $H_{r}$ is an index that helps assess the flowability of the powder. According to Goyal et al. [30], for excellent compressibility and flowability, the $C(\%)$ and $H_{r}$ should be lower than $10 \%$ and 1.11 , respectively. The $H_{r}$ and $C$ values measured in this study, are presented in Figure $4 \mathrm{~b}$. When looking at all powder types, a good correlation is observed between the $H_{r}$ values and number of reuse cycles as well as Carr index and number of reuse cycles, such that an increase in these metrics is observed with an increase in number of reuse cycles. For the most part, the $H_{r}$ and $C$ values for the powder blends lie between their respective genesis powders. All the values indicate that the flowability and compressibility is excellent (as defined by Goyal et al. [30]); however, the increasing trend suggests a degradation in the powder flowability characteristics. These plots strongly indicate that the powder has deteriorated from its virgin state. Specifically, a 3\% and 30\% increase was observed in the $\mathrm{Hr}$ and C values, respectively, for $G_{3}$ powder when compared to the $G_{0}$ powder. This observation is also supported by the general increase of PSD and changes in powder morphology observed as a function of increased reuse cycles.

This degradation of flow properties of the powder blends, as well as the reused individual genesis powders is attributed to the deviation in the powder morphology as observed in the SEM micrographs (Figure 2). Such deviations from the spherical morphology are expected to not only decrease flowability but may also lead to uneven layer formation during raking and ultimately may result in powder bed non-uniformity across the build bed, as mentioned in Table 1. On the other hand, the virgin ( or $\mathrm{G}_{0}$ ) powder is observed to be more spherical and therefore flows easily due to lower surface friction and mechanical interlocking, thus displaying a lower value for $H_{r}$ and $C$ metrics. The packing ability of powder particles influences the sintering of the powder layer [31]. As Neira-Arce [32] describes, uniform and homogeneous layers are crucial to ensure that there is proper heat conduction and for achieving dimensional accuracy, which in turn reduces the risk of swelling or overheating in EB-PBF parts.

The BFE and SE (Figure $5 b$ ) values for the reused powders and blends have also increased with an increase in number of reuse cycles. Specifically, an $18 \%$ and $15 \%$, increase was observed in the BFE and $S E$ values, respectively, for $G_{3}$ powder when compared to the $\mathrm{G}_{0}$ powder. The effect of larger BFE and smaller bulk density of the powder blends might result in a more uneven layer distribution. When looking at the individual genesis powders (Figure 5b), it can be concluded that both BFE and SE show an increase in values with an increase in number of reuse cycles, with $\mathrm{G}_{3}$ being an exception. Similarly, there is a good correlation between BFE and SE (Figure 5a), for all powder types, where an increase in BFE leads to an increase in the SE values.

Strondl et al. [5] observed similar results in EB-PBF powders where the BFE and SE values increased after reusing. Clayton et al. [33] also compared the BFE results for virgin and reused powders and concluded that processing significantly increases the BFE values for reused powders.

Both BFE and SE results suggest that the reused powders and blends would not flow as freely as $G_{0}$. The energy to move the blade in the rheometer is increasing for the reused powders and blends mainly due to their deviation from an overall spherical shape (affected by the pre-heating, blasting and sieving procedures), which causes greater interparticle interactions during testing of the powder samples in the FT4 instrument. As explained by Clayton et al. [33], a higher SE indicates increased mechanical interlocking and friction between particles that may potentially lead to flow problems. An interesting observation is that the BFE and $S E$ values for the $G_{3}$ powder is lower than the $G_{2}$ powder. The reason behind this behavior is not well understood, and therefore this powder type needs to be studied more extensively. However, the authors speculate that the blends have a much higher concentration of non-spherical particles when compared to their respective genesis powders. This may be due to the fact that these powders were exposed to rolling/tumbling over a cumulative time of $48 \mathrm{~h}$. This tumbling procedure may have caused increased physical deformation to the blended powders when compared to the individual genesis powders. 


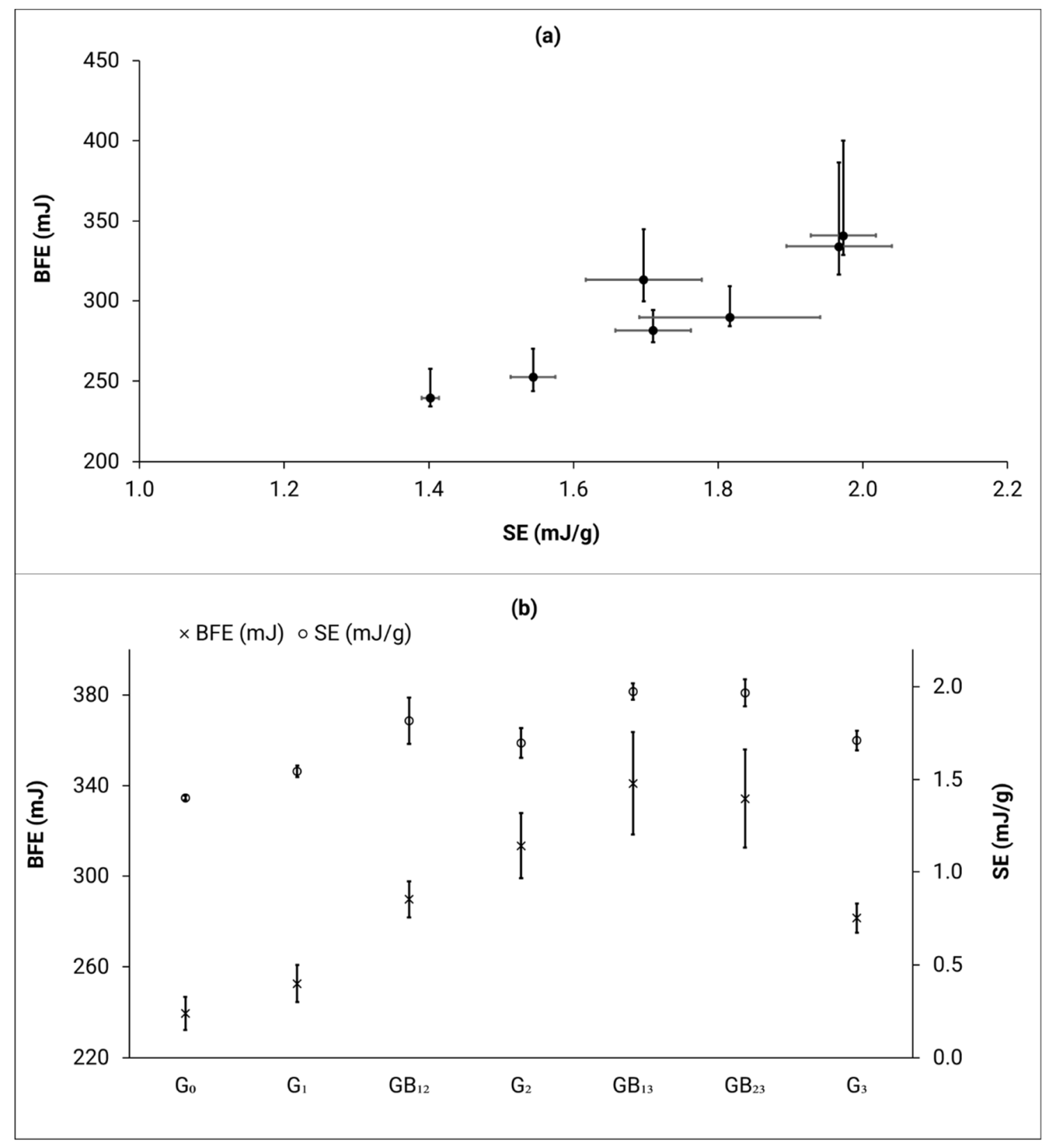

Figure 5. (a) BFE vs. SE, (b) BFE and SE values; for all powder types. Error bars represent the min-max range.

Figure 6a presents a plot of the dynamic angle of repose vs. rotating drum speed for all powder types. It is observed that below $25 \mathrm{rpm}$, it is difficult to make a differentiation between the various powders and all powder have excellent flowability at $2 \mathrm{rpm}$. Above $25 \mathrm{rpm}$, the AOR decreases with an increase in number of reuse cycles. As an example, from Figure $6 c$, it can be observed that at the highest speed (i.e., $60 \mathrm{rpm}$ ), the AOR decreases from $\mathrm{G}_{1}$ to $\mathrm{G}_{3}$. It should be noted that $\mathrm{G}_{0}$ stands out, probably because this powder has not undergone any processing in the machine (pre-heating, blasting, sieving).

The AOR values at the lowest and highest drum rotation speed (i.e., $2 \mathrm{rpm}$ and $60 \mathrm{rpm}$ respectively) were correlated with the particle size $\mathrm{D}_{10}, \mathrm{D}_{50}$, and $\mathrm{D}_{90}$ values. As can be seen from Figure 6e,f, an excellent correlation is observed where an increase in particle size leads to a decrease in the AOR value. It is recognised that larger particles tend to flow more easily than finer powder. It has been observed that the $D_{10}, D_{50}$, and $D_{90}$ values increase with an increase in number of reuse cycles. Therefore, this increase in particle size 
is leading to a better flow in the rotating drum, thus suggesting that the flowability of the reused powders is better in this instrument.

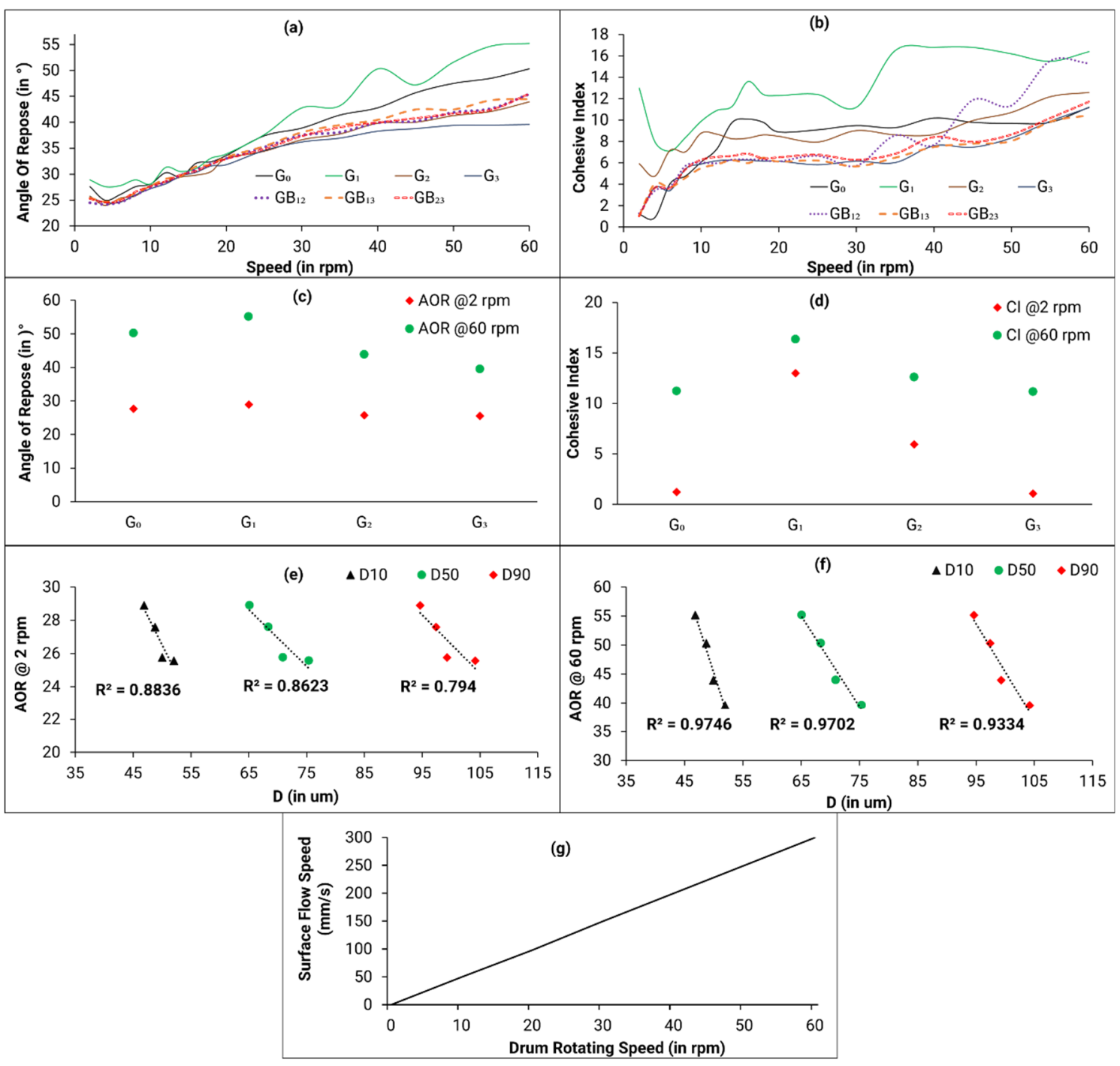

Figure 6. (a) AOR vs. speed of drum rotation for all powder types; (b) CI vs. speed of drum rotation for all powder types; (c) AOR at 2 and $60 \mathrm{rpm}$ vs. number of reuse cycles; (d) CI at 2 and $60 \mathrm{rpm}$ vs. number of reuse cycles; (e) AOR at 2 rpm vs. particle size (D values) for individual genesis powder types; (f) AOR at $60 \mathrm{rpm}$ vs. particle size (D values) for individual genesis powder types; (g) relationship between drum rotating speed and surface flow speed (Redrawn from [34]). Note than $\mathrm{G}_{0}$ powder is considered an anomaly due to the fact that it has not undergone any processing, blasting, or sieving procedure.

Figure $6 \mathrm{~b}$ presents the cohesive index $(\mathrm{CI})$ at various drum rotation speeds for all powder types. The $\mathrm{CI}$ metric is linked to the fluctuations of the interface between the powder and air. The dynamic cohesive index of a powder depends on the magnitude of the cohesive forces between the particles. Therefore, a value closer to zero corresponds to a non-cohesive powder. Per the flow guidelines provided in the GranuDrum instrument software (Version 4.07, Granutools, Liège, Belgium), threshold values for cohesive index are: $<5$ very good, $5-10$ good, $10-20$ fair, $20-30$ passable, $30-40$ poor, $>40$ very poor. The CI follows the same trend (as observed in Figure $6 \mathrm{~b}, \mathrm{~d}$ ) as the AOR curves, where an increase in the number of reuse cycles leads to a decrease in the $C I$ value (except $G_{0}$ ).

The GranuDrum data interpretation guide mentions that the flowability of a powder is measured as a function of the shearing rates, and therefore rheological properties such as shear thinning or shear thickening could be evaluated with this instrument. If the 
powder AOR and CI increase with an increase in drum speed, the powder is said to show a shear-thickening behavior. All powders in this study show a shear-thickening behavior (Figure 6a,b). A powder material that shows a constant shear-thickening behavior is known to be a poor candidate for a dynamic process. That being said, there are portions in the CI vs. drum rotation speed curve (Figure $6 \mathrm{~b}$ ) where a somewhat constant cohesive index can be observed between speeds of $15 \mathrm{rpm}$ and $40 \mathrm{rpm}$. The GranuDrum instrument (Granutools, Liège, Belgium) helps identify an optimum raking/re-coating speed. The relationship between the drum rotating speed and surface flow speed (i.e., raking speed in $\mathrm{mm} / \mathrm{s}$ ) is displayed in Figure 6g. It has been mentioned by the machine manufacturer [34,35], that when selecting raking speeds, one should look at areas that display a constant cohesive index.

As mentioned earlier, drum rotating speeds between $15 \mathrm{rpm}$ and $40 \mathrm{rpm}$ (corresponding to $75 \mathrm{~mm} / \mathrm{s}$ and $175 \mathrm{~mm} / \mathrm{s}$, respectively, according to Figure $6 \mathrm{~g}$ ) show a constant cohesive index. Therefore, raking speeds between $75 \mathrm{~mm} / \mathrm{s}$ and $175 \mathrm{~mm} / \mathrm{s}$ should be considered when using powders for EB-PBF processes.

The effect of powder reuse on interparticle cohesion is contrary to the measurements done with FT4 instrument (higher BFE and SE with reuse). It is not clear at the moment whether the increase of the PSD with reuse is only associated with the agglomeration, the sieving, or a combination of both. Difference in flow regime and the sensitivity of the flowability to multiple powder modifications may explain the discrepancy in these results.

As mentioned by Brika et al. [16], powder flowability is not an inherent material property and is the ability of the powder to flow in a desired manner in a particular instrument. A powder may perform well in a certain instrument/piece of equipment while it may perform poorly in another. Thus, additional tests are required to better understand which regime better represents the behavior of the powder in an additive manufacturing (AM) machine.

Figure $7 \mathrm{a}, \mathrm{b}$ show that the average values for oxygen and nitrogen concentration increase with the number of reuse cycles. Specifically, a $37 \%$ and $44 \%$ increase was observed in the oxygen and nitrogen concentration, respectively, for $\mathrm{G}_{3}$ powder when compared to the $\mathrm{G}_{0}$ powder. However, the oxygen concentration remains lower than $0.18 \mathrm{wt} . \%$ and below the limit outlined by ASTM F2924-14 [11]. A logarithmic trendline seems to better fit the results when compared to the linear trendline (Figure 7a). From the logarithmic trendline, it can be deduced that the $\mathrm{O}_{2}$ concentration will exceed the $0.2 \mathrm{wt} . \%$ limit by $5-6$ reuse cycles. The nitrogen concentration remains between $0.016 \mathrm{wt} . \%$ and $0.023 \mathrm{wt} . \%$ (Figure 7b), which is well below the $0.05 \mathrm{wt} . \%$ limit outlined by ASTM 2924-14 [11]. An increase of nitrogen concentration with the number of reuse cycles is observed; the logarithmic trend line suggests that this nitrogen pickup may reach a saturation level, suggesting that this is a surface contamination (formation of nitride or local concentration at the surface). The trend suggests that the maximum (i.e., $0.05 \mathrm{wt} . \%$ ) will not be reached before a large number of reuse cycles.

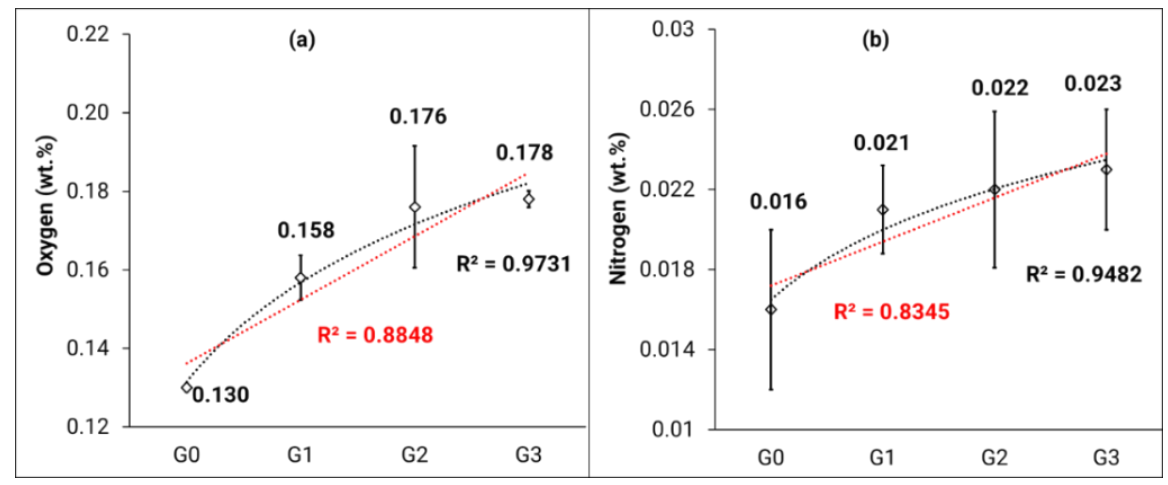

Figure 7. (a) Oxygen and (b) nitrogen concentration for $G_{0}, G_{1}, G_{2}$, and $G_{3}$ powder types along with linear (in red) and logarithmic (in black) trendlines. Error bars represent the standard deviation. 
Some other studies have also looked at the increase in oxygen and nitrogen content with an increase in number of reuse cycles. Ghods et al. [36] showed that the oxygen content was $>0.20 \mathrm{wt} . \%$ after 11 reuse cycles. Grainger [29] observed a linear increase in oxygen and nitrogen concentrations in Grade $23 \mathrm{Ti}-6 \mathrm{Al}-4 \mathrm{~V}$ powder after reusing in the laser PBF process. However, after 30 builds, the oxygen concentration remained below $0.20 \mathrm{wt} . \%$. These values are attributed to the fact that the starting oxygen concentration in Grade 23 Ti-6Al-4V is much lower than that of Grade 5 Ti-6Al-4V. Nandwana et al. [37] observed an increase in the oxygen concentration from $0.13 \mathrm{wt} . \%$ to $0.18 \mathrm{wt} . \%$; however, their nitrogen concentration remained the same over five reuse cycles for a Ti-6Al-4V powder.

There are numerous factors which contribute to oxygen pickup in Ti- $6 \mathrm{Al}-4 \mathrm{~V}$ powders processed through EB-PBF. One of the possible reasons for the increase of oxygen pickup is the fact that the powder is exposed to the ambient atmosphere and moisture when transferred from the machine to the PRS for part recovery, and then transferred from the PRS to the sieve. A study performed by Vluttert [38] shows that Ti-6Al-4V can pick up about $0.2 \mathrm{wt}$. \% moisture (relative to dry weight) when left in an environment that was set to $25{ }^{\circ} \mathrm{C}$ and $90 \%$ humidity. Therefore, the presence of water vapor in the air may have a reasonable impact on oxygen pickup. Montelione et al. [39] compare the EB-PBF process to gas tungsten arc welding and suggest that when the powder is exposed to air, the water molecules adsorbed on the particle surface may dissociate during heating, allowing the oxygen to diffuse in the metal alloy. In addition, the deformation caused by blasting and sieving can also lead to an acceleration of the oxidation due to creation of new oxidation prone surfaces. Shvab et al. [40] describe that this will lead to a passive oxide layer formation that may diffuse inward and reform during heating cycles. This oxide layer may also translate into the melt pool upon melting, and cause instabilities that form balling defects, thus hindering part consolidation [41]. Furthermore, oxygen pickup can also occur if the machine is not under vacuum, when the powder is stored in the hoppers, in between the builds. Finally, the major source of oxygen pickup is the reaction of titanium at high temperature with residual oxygen in the atmosphere of the machine. In addition, Mizuno et al. [42] noted that all oxides in titanium alloys dissolve above $400{ }^{\circ} \mathrm{C}$ and the oxygen diffuses into the bulk through the bulk diffusion process.

The EB-PBF process takes place at a relatively high temperature where the titanium can react with residual oxygen. Moreover, the high temperature can also result in oxygen diffusion as described by Attalla et al. [43] (build chamber $\approx 10^{-4}$ mbar and electron beam column $\approx 10^{-7} \mathrm{mbar}$ ). The oxygen and nitrogen can dissolve interstitially into the titanium lattice during solidification of the melt pool, and form oxides and nitrides [36]. Such oxides and nitrides are known to be detrimental to the fatigue performance of manufactured parts [44]. As stated by Donachie [45], an increase in the oxygen and nitrogen content in solution can lead to an increase in the strength and decrease in the ductility which further leads to embrittlement.

\subsection{Evaluation of the Relative Performance of Powders}

It is quite challenging to deploy a unified metric to capture the absolute suitability of powders for PBF AM processes. The powder metrics measured are highly different in nature and may impact the PBF process and final part properties in different ways. For instance, powder metrics variations may have opposite effects, i.e., some characteristics may lead to an improved behavior in the AM process, others may lead to a deterioration of the AM process behavior, while some powder metrics may have limited effect. In literature, this is poorly understood at the moment. Variability is still relatively high for some of the powder measurement techniques, and is influenced by the testing equipment type, the testing conditions, the powder storage and handling conditions, the operator skill, the calibration of instruments, and many other factors. Care must be exercised in interpreting each powder metric result individually. Although it is challenging to capture the absolute suitability of powders for PBF AM processes via a consolidated index, there is a potential to describe the relative change in powder properties with respect to a reference state, if 
such reference should exist. A reference state, for instance, is often considered to be the virgin powder. Two examples of calculations of relative changes from a reference state are presented below.

\subsubsection{Relative Performance Evaluated via Radar Diagram}

To understand the sensitivity of response to change of the various powder characteristics from a reference powder $\left(\mathrm{G}_{0}\right.$ in this work), the various properties measured were normalized to a range of 0 to 1 and a radar diagram of the normalized indices for the $G_{0}$, $\mathrm{G}_{1}, \mathrm{G}_{2}$, and $\mathrm{G}_{3}$ powders was plotted in Figure 8. The normalization was done to transform the data into a dimensionless data sequence for ease of comparability. For this study, the approach used for normalizing all metrics was taken from Mehat et al. [46]:

$$
x_{i}^{*}(\mathrm{k})=\frac{x_{i}^{(0)}(\mathrm{k})-\min x_{i}^{(0)}(\mathrm{k})}{\max x_{i}^{(0)}(\mathrm{k})-\min x_{i}^{(0)}(\mathrm{k})}
$$

where $x_{i}^{(0)}(\mathrm{k})$ is the measurement of the quality characteristic, max $x_{i}^{(0)}(\mathrm{k})$ is the largest value of $x_{i}^{(0)}(\mathrm{k})$, and $\min x_{i}^{(0)}(\mathrm{k})$ is the smallest value of $x_{i}^{(0)}(\mathrm{k})$.

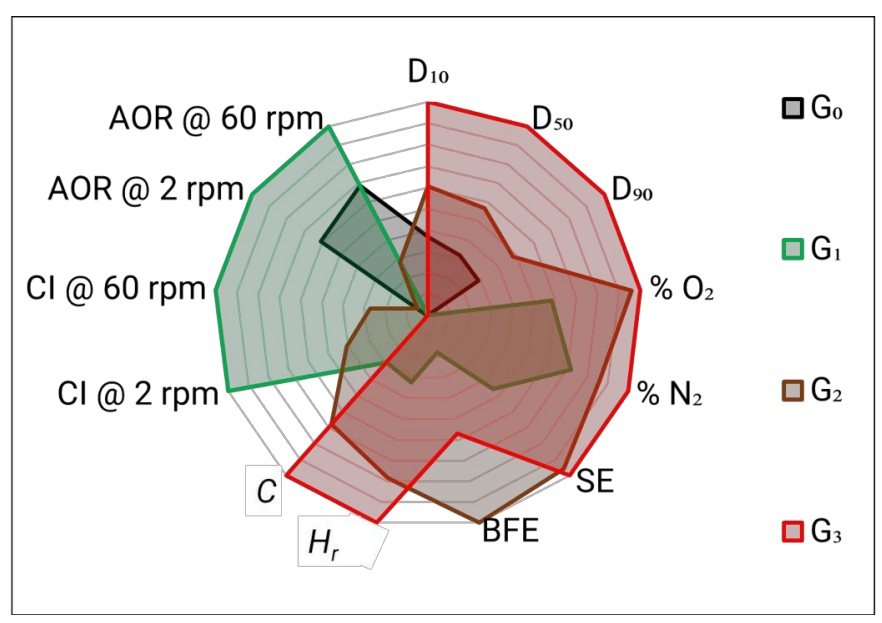

Figure 8. Radar diagram comparing the performance of $G_{0}, G_{1}, G_{2}$, and $G_{3}$ powders w.r.t the $D$ values, SE, BFE, nitrogen (in wt.\%), oxygen (in wt.\%), $\mathrm{Hr}, \mathrm{C}, \mathrm{CI}$, and $\mathrm{AOR}$.

In accordance with the powder suitability criteria created in Figure 8, the smaller the area covered by the radar diagram, the higher the powder suitability for the EB-PBF process. It is observed that the $G_{0}$ powder has the smallest area, followed by $G_{1}, G_{2}$, and $\mathrm{G}_{3}$, indicating that the powder is becoming less suitable with the increasing number of reuse cycles.

In this study, the authors evaluate the reused powders through various performance metrics such as morphology, size distribution, basic flow energy, specific energy, bulk density, tap density, Hausner ratio, Carr index, cohesive index, angle of repose, oxygen content, and nitrogen content. Each metric contributes additional knowledge and information regarding the powders, as per Table 1 . However, performing all of these tests can be extremely time-consuming and expensive. Furthermore, acquiring results for all these metrics may not necessarily be relevant to a specific user or application. Therefore, it is up to the user to determine which tests are relevant for their own work based on the information that is provided for each characterization technique (Table 1 may be used for this purpose). For example, a user looking at manufacturing parts for aerospace applications will need to adhere by ASTM F2924-14, and therefore this user must evaluate the $\% \mathrm{O}_{2}$ and $\% \mathrm{~N}_{2}$. Conversely, if a user is looking at manufacturing medical models solely for the purpose of education and training, then they may require good dimensional accuracy and surface finish for their model. Therefore, they must evaluate the particle size distribution 
(D values) and flowability metrics (e.g., BFE and SE) as these affect the layer homogeneity, proper spreading upon raking, minimum feature size, and surface finish as described in Table 1.

\subsubsection{Relative Performance Evaluated via Performance Index}

Efforts in assessing powder suitability for powder bed fusion were undertaken by Brika et al. [16]; they differentiated powders and assessed three powder types by calculating a figure of merit called AMS (additive manufacturing suitability). While in this present study, the authors are not assessing an absolute suitability criterion due to challenges aforementioned; this approach is deployed herein to assess if this index can be used to quantify the relative changes in powder properties with respect to a reference state $\left(G_{0}\right.$ in this work). Since the current study focuses on EB-PBF powder suitability, the index will be referred as "ESF" (electron beam powder bed fusion suitability factor) and is inspired from Brika et al. [16]. As such, for each powder reuse cycle, a cumulative sum of the normalized index presented in Figure 8 will provide an objective function:

$\mathrm{ESF}=\frac{\left(\mathrm{D}_{10}+\mathrm{D}_{50}+\mathrm{D}_{90}+\mathrm{O}_{2}+\mathrm{N}_{2}+\mathrm{SE}+\mathrm{BFE}+\mathrm{H}_{r}+\mathrm{C}+\mathrm{CI} @ 2 \mathrm{rpm}+\mathrm{CI} @ 60 \mathrm{rpm}+\mathrm{AOR} @ 2 \mathrm{rpm}+\mathrm{AOR} @ 60 \mathrm{rpm}\right)}{13}$

The ESF values for $G_{0}, G_{1}, G_{2}$, and $G_{3}$ powders are $0.176,0.504,0.609$, and 0.659, respectively. It is assumed that the lower deviation from the ESF value with respect to $G_{0}$, the more the properties of the powder will depart from the reference state. This is another example of efforts towards expressing the relative change in powder characteristics.

As a conclusion, this study looked into comparing the influence of multiple reuse cycles, as well as powder blends created from reused powder, through various performance metrics such as morphology, size distribution, basic flow energy, specific energy, bulk density and tap density after 500 taps, Hausner ratio and Carr index, cohesive index, angle of repose, oxygen content, and nitrogen content. In accordance with the authors' hypotheses established in Shanbhag and Vlasea [23], it was observed that reusing modifies the powder significantly when assessing the various performance metrics. While parts were printed during this study, no significant differences were observed during the different build cycles or general appearance of the printed components. The evaluation of the reuse of the powder on the microstructure and properties of the parts was beyond the scope of this study. Future research efforts will rely on this present study and will look into assessing the microstructure and mechanical properties of the parts to be able to understand the impact of reusing powders on part performance.

\section{Conclusions}

Investigation into the effect of plasma-atomized Grade $5 \mathrm{Ti}-6 \mathrm{Al}-4 \mathrm{~V}$ powder reuse on the powder properties as well as properties of powder blends led to the following conclusions:

(1) The SEM micrographs of the various powder types show extensive physical modification to the surface of the particles, with increasing degree of powder reuse. The micrographs depict features such as elongated particles, broken particles, clip-clap, deformed particles, particle with molten specks, and agglomerates. The broke, shattered, clip-clap, and deformed particles are attributed to the powder recovery process (i.e., blasting, sieving) and tumbling process; the particles with molten specks, elongated particles, and agglomerated particles are attributed to the high temperature conditions leading to overheating and smelting of particles and satellites.

(2) The $\mathrm{D}_{10}, \mathrm{D}_{50}$, and $\mathrm{D}_{90}$ values increase with increasing degree of powder reuse. Specifically, a $7 \%, 10 \%$, and $7 \%$ increase was observed in the $\mathrm{D}_{10}, \mathrm{D}_{50}, \mathrm{D}_{90}$ values, respectively, for $\mathrm{G}_{3}$ powder when compared to the $\mathrm{G}_{0}$ powder. This observation is attributed to the agglomeration of powder particles.

(3) The $\rho_{0}$ remained unchanged for all powders, however, the $\rho_{500}$ increases with increasing degree of powder reuse. Specifically, a 3\% increase was observed in the $\rho_{500}$ value for $\mathrm{G}_{3}$ powder when compared to the $\mathrm{G}_{0}$ powder. The $H_{r}$ and $C$ values show 
an increase with an increase in number of reuse cycles. Specifically, a 3\% and 30\% increase was observed in the $H_{r}$ and $C$ values, respectively, for $\mathrm{G}_{3}$ powder when compared to the $G_{0}$ powder. This trend indicates modification of reused powders from their virgin state. These observations have been attributed to the deviations from spherical morphology, for the reused powder, as observed in the SEM micrographs. Due to these deviations, uneven raking and non-homogenous layers may be obtained.

(4) The BFE and SE values increase with increasing degree of powder reuse. This suggests that the reused powder is more cohesive than the virgin powder. Specifically, an $18 \%$ and $15 \%$, increase was observed in the BFE and SE values, respectively, for $\mathrm{G}_{3}$ powder when compared to the $\mathrm{G}_{0}$ powder. This behavior is attributed to the mechanical interlocking and friction between particles (caused by the non-spherical morphology).

(5) The dynamic AOR and CI values decrease with an increase in the number of reuse cycles. This behavior is attributed to the agglomeration and increase of the $\mathrm{D}_{10}, \mathrm{D}_{50}$, and $D_{90}$ with the number of reused cycles. The variations of the metrics with drum rotating speed may help identify a range of optimum raking speeds that can be used for these powders when being used in the EB-PBF machine.

(6) The $\mathrm{O}_{2}$ and $\mathrm{N}_{2}$ concentration remain below the limits outlined by ASTM F2924. However, a gradual increase has been observed with increasing degree of powder reuse. Specifically, a $37 \%$ and $44 \%$ increase was observed in the $\mathrm{O}_{2}$ and $\mathrm{N}_{2}$ concentration, respectively, for $\mathrm{G}_{3}$ powder when compared to the $\mathrm{G}_{0}$ powder. From the logarithmic trendline, it can be deduced that the $\mathrm{O}_{2}$ concentration will exceed the $0.2 \mathrm{wt} . \%$ limit by $5-6$ reuse cycles.

(7) A unified powder quality score or powder quality metric was established to compare the effect of powder reuse on the various powder performance metrics.

Author Contributions: Conceptualization, G.S. and M.V.; investigation, G.S.; methodology, G.S.; project administration, G.S.; supervision, M.V.; writing—original draft, G.S.; writing-review and editing, M.V.; funding acquisition, M.V. All authors have read and agreed to the published version of the manuscript.

Funding: The authors appreciate the partial funding support received from the Natural Sciences and Engineering Research Council (NSERC) Holistic Innovation in Additive Manufacturing (HI-AM) grant NETGP 494158-16. The authors also appreciate the research contributions and funding support from the National Research Council, Canada (NRC) under the "Additive Manufacturing Materials and Processes" collaboration program 080531, sub-project SUB03280.

Institutional Review Board Statement: Not applicable.

Informed Consent Statement: Not applicable.

Data Availability Statement: The data presented in this study are available on request from the corresponding author.

Acknowledgments: The authors would like to acknowledge Louis-Philippe Lefebvre, Research Officer at National Research Council Canada, for his significant efforts in the review of the paper, in providing editorial comments, scientific and technical feedback. In addition, the authors would like to acknowledge the support from the Multi Scale Additive Manufacturing Lab (MSAM, University of Waterloo) technical staff Jerry Ratthapakdee for assisting with the manufacturing process and interns (specifically Kate Pearson and Cecilia Cancellara) for assisting with powder characterization datasets, as well as Shirley Mercier from NRC for conducting the LECO analysis.

Conflicts of Interest: The authors declare no conflict of interest.

\section{References}

1. Vock, S.; Klöden, B.; Kirchner, A.; Weißgärber, T.; Kieback, B. Powders for powder bed fusion: A review. Prog. Addit. Manuf. 2019, 4, 383-397. [CrossRef]

2. Popov, V.V.; Grilli, M.L.; Koptyug, A.; Jaworska, L.; Katz-Demyanetz, A.; Klobčar, D.; Balos, S.; Postolnyi, B.O.; Goel, S. Powder Bed Fusion Additive Manufacturing Using Critical Raw Materials: A Review. Materials 2021, 14, 909. [CrossRef] [PubMed]

3. German, R.M. Particle Packing Characterisitics; Metal Powder Industries Federation: Princeton, NJ, USA, 1989. 
4. Yang, L.; Hsu, K.; Baughman, B.; Godfrey, D.; Medina, F.; Menon, M.; Wiener, S. Additive Manufacturing of Metals: The Technology, Materials, Design and Production; Springer International Publishing: Cham, Switzerland, 2017; pp. 63-79.

5. Strondl, A.; Lyckfeldt, O.; Brodin, H.; Ackelid, U. Characterization and Control of Powder Properties for Additive Manufacturing. JOM 2015, 67, 549-554. [CrossRef]

6. Medina, F. Reducing Metal Alloy Powder Costs for Use in Powder Bed Fusion Additive Manufacturing: Improving The Economics for Production; University of Texas El Paso: El Paso, TX, USA, 2013.

7. Entezarian, M.; Allaire, F.; Tsantrizos, P.; Drew, R.A.L. Plasma atomization: A new process for the production of fine, spherical powders. JOM 1996, 48, 53-55. [CrossRef]

8. Simchi, A. The role of particle size on the laser sintering of iron powder. Metall. Mater. Trans. B 2004, 35, 937-948. [CrossRef]

9. Angelo, P.C.; Subramaniam, R. Powder Metallurgy: Science, Technology and Applications; PHI Learning Pvt. Ltd.: Delhi, India, 2008.

10. Teferra, T.F. Engineering Properties of Food Materials. In Handbook of Farm, Dairy and Food Machinery Engineering; Elsevier: Norwich, NY, USA, 2019; pp. 45-89.

11. ASTM F2924-14. Standard Specification for Additive Manufacturing Titanium-6 Aluminum-4 Vanadium with Powder Bed Fusion; ASTM International: West Conshohocken, PA, USA, 2014. [CrossRef]

12. DebRoy, T.; Mukherjee, T.; Milewski, J.O.; Elmer, J.W.; Ribic, B.; Blecher, J.J.; Zhang, W. Scientific, technological and economic issues in metal printing and their solutions. Nat. Mater. 2019, 18, 1026-1032. [CrossRef]

13. Hopkinson, N.; Dicknes, P. Analysis of rapid manufacturing-using layer manufacturing processes for production. Proc. Inst. Mech. Eng. Part C J. Mech. Eng. Sci. 2003, 217, 31-39. [CrossRef]

14. Baumers, M.; Dickens, P.; Tuck, C.; Hague, R. The cost of additive manufacturing: Machine productivity, economies of scale and technology-push. Technol. Forecast. Soc. Chang. 2016, 102, 193-201. Available online: https:/ / econpapers.repec.org/RePEc:eee: tefoso:v:102:y:2016:i:c:p:193-201 (accessed on 11 August 2021). [CrossRef]

15. Grell, W.A.; Solis-Ramos, E.; Clark, E.; Lucon, E.; Garboczi, E.J.; Predecki, P.K.; Loftus, Z.; Kumosa, M. Effect of powder oxidation on the impact toughness of electron beam melting Ti-6Al-4V. Addit. Manuf. 2017, 17, 123-134. [CrossRef]

16. Brika, S.E.; Letenneur, M.; Dion, C.A.; Brailovski, V. Influence of particle morphology and size distribution on the powder flowability and laser powder bed fusion manufacturability of Ti-6Al-4V alloy. Addit. Manuf. 2020, 31, 100929. [CrossRef]

17. Moghimian, P.; Poirié, T.; Habibnejad-Korayem, M.; Zavala, J.A.; Kroeger, J.; Marion, F.; Larouche, F. Metal powders in additive manufacturing: A review on reusability and recyclability of common titanium, nickel and aluminum alloys. Addit. Manuf. 2021, 43, 102017. [CrossRef]

18. Tang, H.P.; Qian, M.; Liu, N.; Zhang, X.Z.; Yang, G.Y.; Wang, J. Effect of Powder Reuse Times on Additive Manufacturing of Ti-6Al-4V by Selective Electron Beam Melting. J. Miner. Met. Mater. Soc. 2015, 67, 555-563. [CrossRef]

19. Mohammadhosseini, A.; Fraser, D.; Masood, S.H.; Jahedi, M. A Study of Morphology of Titanium Powder Used in Electron Beam Melting. In Engineering and Manufacturing Technologies; Trans Tech Publications Ltd.: Zurich, Switzerland, 2014; Volume 541, pp. 160-163. [CrossRef]

20. Sun, Y.; Aindow, M.; Hebert, R.J. The effect of recycling on the oxygen distribution in Ti-6Al-4V powder for additive manufacturing. Mater. High Temp. 2018, 35, 217-224. [CrossRef]

21. Petrovic, V.; Niñerola, R. Powder recyclability in electron beam melting for aeronautical use. Aircr. Eng. Aerosp. Technol. 2015, 87, 147-155. [CrossRef]

22. Leung, C.L.A.; Marussi, S.; Towrie, M.; Atwood, R.C.; Withers, P.J.; Lee, P.D. The effect of powder oxidation on defect formation in laser additive manufacturing. Acta Mater. 2019, 166, 294-305. [CrossRef]

23. Shanbhag, G.; Vlasea, M. The effect of reuse cycles on Ti-6Al-4V powder properties processed by electron beam powder bed fusion. Manuf. Lett. 2020, 25, 60-63. [CrossRef]

24. ISO 13322-2. Particle size analysis_Image analysis methods_Part 2: Dynamic image analysis methods; International Organization for Standardization: Geneva, Switzerland, 2006; Volume 2. Available online: https:/ / www.iso.org/standard/38665.html (accessed on 11 August 2021).

25. Freeman, R.; Fu, X. Characterisation of powder bulk, dynamic flow and shear properties in relation to die filling. Powder Metall. 2008, 51, 196-201. [CrossRef]

26. Popov, V.V.; Katz-Demyanetz, A.; Garkun, A.; Bamberger, M. The effect of powder recycling on the mechanical properties and microstructure of electron beam melted Ti-6Al-4 V specimens. Addit. Manuf. 2018, 22, 834-843. [CrossRef]

27. Cordova, L.; Campos, M.; Tinga, T. Revealing the Effects of Powder Reuse for Selective Laser Melting by Powder Characterization. JOM 2019, 71, 1062-1072. [CrossRef]

28. Slotwinski, J.A.; Garboczi, E.J.; Stutzman, P.E.; Ferraris, C.F.; Watson, S.S.; Peltz, M.A. Characterization of Metal Powders Used for Additive Manufacturing. J. Res. Natl. Inst. Stand. Technol. 2014, 119, 460. [CrossRef]

29. Grainger, L. Investigating the Effects of Multiple Re-Use of Ti6Al4V Powder in Additive Manufacturing (AM). Available online: https:/ / resources.renishaw.com/en/details/white-paper-investigating-the-effects-of-multiple-powder-re-use-in-am-83164 (accessed on 11 August 2021).

30. Goyal, A.; Sharma, V.; Sihag, M.K.; Tomar, S.K.; Arora, S.; Sabikhi, L.; Singh, A.K. Development and physico-chemical characterization of microencapsulated flaxseed oil powder: A functional ingredient for omega-3 fortification. Powder Technol. 2015, 286, 527-537. [CrossRef] 
31. Gong, X.; Anderson, T.; Chou, K. Review on powder-based electron beam additive manufacturing technology. Manuf. Rev. 2014, 1, 2. [CrossRef]

32. Neira-Arce, A. Thermal Modeling and Simulation of Electron Beam Melting for Rapid Prototyping on Ti6Al4V Alloys; North Carolina State University: Raleigh, NC, USA, 2012.

33. Clayton, J.; Millington-Smith, D.; Armstrong, B. The Application of Powder Rheology in Additive Manufacturing. JOM 2015, 67, 544-548. [CrossRef]

34. Granutools. Linking Powder Rheology Characterization to Spreadability in Powder Bed-Based AM. AZO Mater. 2020. Available online: https: / / www.azom.com/article.aspx?ArticleID=19335 (accessed on 23 April 2021).

35. Granutools. Effect of Recycling on the Spreadability of Metallic Powder. AZO Mater. 2020. Available online: https://www.azom. com/article.aspx?ArticleID=19313 (accessed on 23 April 2021).

36. Ghods, S.; Schultz, E.; Wisdom, C.; Schur, R.; Pahuja, R.; Montelione, A.; Arola, D.; Ramulu, M. Electron beam additive manufacturing of Ti6Al4V: Evolution of powder morphology and part microstructure with powder reuse. Materialia 2020, 9, 100631. [CrossRef]

37. Nandwana, P.; Peter, W.H.; Dehoff, R.R.; Lowe, L.E.; Kirka, M.M.; Medina, F.; Babu, S.S. Recyclability Study on Inconel 718 and Ti-6Al-4V Powders for Use in Electron Beam Melting. Metall. Mater. Trans. B 2016, 47, 754-762. [CrossRef]

38. Vluttert, N. The Absorption of Moisture by Metal Powder in A Humid Environment and the Effects on Its Composition. Bachelor's Thesis, University of Twente, Enschede, The Netherlands, 2016. Available online: http:/ / essay.utwente.nl/71620/ (accessed on 23 April 2021).

39. Montelione, A.; Ghods, S.; Schur, R.; Wisdom, C.; Arola, D.; Ramulu, M. Powder Reuse in Electron Beam Melting Additive Manufacturing of Ti6Al4V: Particle Microstructure, Oxygen Content and Mechanical Properties. Addit. Manuf. 2020, $35,101216$. [CrossRef]

40. Shvab, R.; Hryha, E.; Nyborg, L. Surface chemistry of the titanium powder studied by XPS using internal standard reference. Powder Metall. 2017, 60, 42-48. [CrossRef]

41. Tan, J.H.; Wong, W.L.E.; Dalgarno, K.W. An overview of powder granulometry on feedstock and part performance in the selective laser melting process. Addit. Manuf. 2017, 18, 228-255. [CrossRef]

42. Mizuno, Y.; King, F.K.; Yamauchi, Y.; Homma, T.; Tanaka, A.; Takakuwa, Y.; Momose, T. Temperature dependence of oxide decomposition on titanium surfaces in ultrahigh vacuum. J. Vac. Sci. Technol. A Vacuum Surfaces Film 2002, 20, 1716-1721. [CrossRef]

43. Attalla, A.; Bowman, R.C.J.; Craft, B.D.; Love, C.M.; Yauger, R.L. Investigation of Moisture in Titanium Metal Powder by Pulsed NMR; Mound Lab.: Miamisburg, OH, USA, 1977. [CrossRef]

44. Sims, C.T.; Stoloff, N.S.; Hagel, W.C. Superalloys II: High-Temperature Materials for Aerospace and Industrial Power; Wiley: Hoboken, NJ, USA, 1987.

45. Donachie, M.J. Titanium: A Technical Guide, 2nd ed.; ASM International: Materials Park, OH, USA, 2000.

46. Mehat, N.M.; Kamaruddin, S.; Othman, A.R. Hybrid Integration of Taguchi Parametric Design, Grey Relational Analysis, and Principal Component Analysis Optimization for Plastic Gear Production. Chin. J. Eng. 2014, 2014, 351206. [CrossRef] 